\title{
Active Share Is a Fuzzy Number
}

\section{HOW CAN MANAGERS AND CLIENTS PREVENT THE MANIPULATION OF "ACTIVE SHARE"?}

By Barry M. Gillman, CFA

"Active share" has gained increasing visibility among investment managers, consultants, and clients since the concept was introduced in 2006 by Martijn Cremers and Antti Petajisto (both at Yale School of Management's International Center for Finance) in their white paper "How Active Is Your Fund Manager? A New Measure That Predicts Performance." Active share's popularity has largely been driven by two factors. First, it appears simple and intuitive; active share is the proportion of a portfolio's holdings that is different from the benchmark for that portfolio. (Thus, a portfolio that has perfectly matched its benchmark composition has an active share of zero, and one that has no holdings in common with its benchmark has an active share of 100.) Second, the investment industry has become fascinated by the debate over the link between the level of active share and outperformance of the benchmark.

But it may not always be as straightforward as it seems. Some managers may be pleased to claim a high active share (with the implication that the measure is a link to good performance), even though the reality is more complex and potentially quite fuzzy!

While active share appears simple, research has shown that any portfolio's active share is significantly dependent on the construction of the index against which it's benchmarked. (For example, see the research paper "Is Your Portfolio's 'Active Share' Really High?" published by the Brandes Institute and SEB Investment Management [www.brandes.com/institute].) In general, the more concentrated the benchmark, the harder it is to achieve an active share in the range generally considered "high" in the industry (80\% plus). For example, a manager of Canadian large caps would struggle to post an active share over $70 \%$, while a US small-cap manager would struggle to get active share below $80 \%$. And the link between active share and outperformance is still being actively debated by academics and practitioners.
Let's use a simplified example for the purpose of illustration. Your portfolio is benchmarked against the S\&P 500 Index, and you have invested the whole portfolio in one stock, which has the ticker symbol "SPY." SPY is not included in the S\&P 500, so the active-share definition would suggest your active share is 100: That is, you have no holdings in common with your benchmark. But

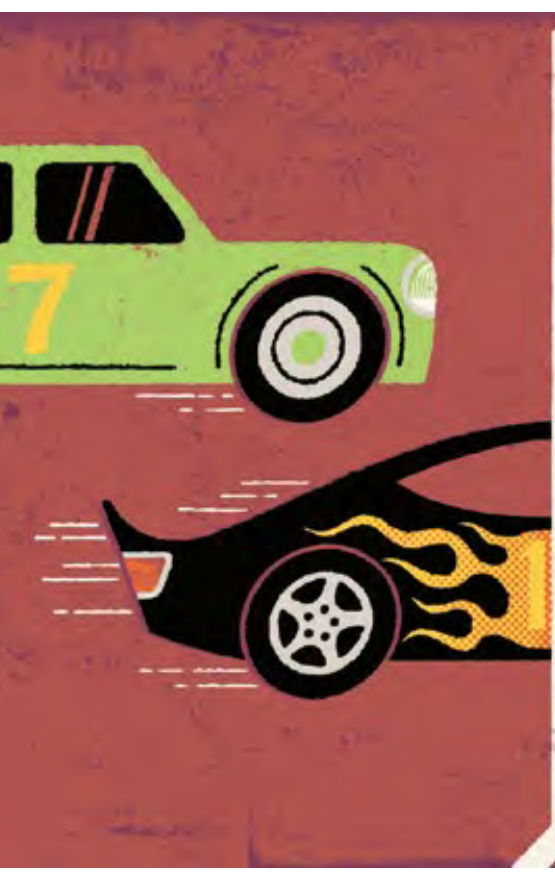

Although these questions about how best to use active share are admittedly important, this article's focus is on the even more fundamental issue of how to measure this number. Measurement is important because active share is well on its way to becoming a central element of managers' sales efforts and of clients' portfolio analytics. The reality, however, is that active share is a fuzzy number, open both to inadvertent errors and to manipulative techniques.

\section{GAMING ACTIVE SHARE}

How is it possible to manipulate active share? After all, the calculation definition seems clear and unambiguous.
SPY is an exchange-traded fund (ETF) designed to mirror the performance of the S\&P 500, so your results should be substantially identical to those of the index-effectively, an active share of close to zero.

That's obviously an extreme case, but it makes the point that, in principle, the system can be gamed. It opens the door to a number of gray areas where, deliberately or inadvertently, managers can tilt active-share statistics in their favor. Why would any manager do this? Because the consensus among active managers and their clients seems to be that if outperformance is linked to active share, then the higher the active 
share, the better.

This assumption hits a manager's bottom line: All else being equal, a higher active share may increase the manager's chances of being hired.

Indeed, managers and regulators in Europe are already engaged in active discussions about four aspects of active share that can lead to gray areas of interpretation: (1) using different securities of the same issuer, (2) disguising the underlying index exposure, (3) cash, and (4) choosing the wrong benchmark.

Different securities from the same issuer. This situation can be a problem if the portfolio holds securities that behave substantially the same as the ordinary shares in the benchmark, such as depositary receipts (e.g., American depositary receipts [ADRs] and global depositary receipts [GDRs]) or different share classes (e.g., A, B, or C shares). These securities aren't in the benchmark, so with a strict definition of active share, holding them would boost active share. A possible remedy is to count active share at the company level rather than the security level, but doing so could also net securities that really don't behave like the ordinary shares, such as convertibles, preference shares, and some of the "letter" share classes, thus reducing active share unnecessarily.

Disguised underlying exposure. Although the earlier illustration of an ETF used to replicate index exposure is an extreme example, the use of derivatives, funds, or synthetic securities can lead to misleading results because none are included in the benchmark. The logical remedy is to "look through" to the underlying exposure. This approach makes more work for managers (which may be philosophically acceptable because they were the ones who decided to use these instruments), but a client will have a hard time trying to verify that the resulting active-share number is reasonable.

Cash. Holding cash is an active decision of the manager and is not in the benchmark, so cash holdings should be counted in the calculation of active share. "Equity-only" active-share

calculations should not be permitted (and because they would lower the active-share result, most managers should be pleased to conform to this standard).

Choice of benchmark. Because active share is by definition calculated relative to a benchmark, using an inappropriate benchmark is a quick way of boosting active share. Detection may not always be easy. For example, suppose a manager's mandate allows the manager to invest across the whole spectrum of the US equity market, so the manager measures the active share against the

\section{UNLESS OR UNTIL A CODE OF CONDUCT MAKES ACTIVE SHARE LESS SUSCEPTIBLE TO "FUZZY" MANIPULATION, MANAGERS AND CLIENTS WILL NEED TO BE AWARE OF THE POTENTIAL PROBLEMS.}

Russell 3000, an all-cap index, and gets a result of $92 \%$. Now, suppose an astute client notes that over the past decade the portfolio has owned only large-cap stocks and that the benchmark could theoretically be the Russell 3000, but a much more appropriate one would be the large-cap Russell 1000. The manager's revised active share drops to, say, $73 \%$ as a result. A possible remedy for this problem is for the manager to use the benchmark that has the highest correlation with their long-term portfolio returns - which, by the way, was the approach used by Cremers and Petajisto, the creators of active share, in their original 2006 research study.

\section{AVOIDING PROBLEMS}

Given the potential for miscommunication, let alone abuse, what should be done to prevent these issues from becoming major problems for clients and advisers?

\section{KEEP GOING}

"Deactivating Active Share," Financial Analysts Journal (posted online 6 January 2016 ahead of publication) [www.cfapubs.org] while claiming a link between that number and outperformance.

Even if regulation is not on the immediate horizon in the US, agreeing on a standardized approach (or "code of conduct") for calculating active share would be advantageous. Managers and their clients would benefit from increased transparency and improved credibility in active-share numbers.

Unless or until a code of conduct makes active share less susceptible to "fuzzy" manipulation, managers and clients will need to be aware of the potential problems. As long as the use of active share remains "unregulated," managers should use their judgment to make sure the active share they claim for their portfolios truly represents the underlying reality. For clients, the goal should be to become sufficiently aware of the potential problems so they can ask their managers the right questions. Defining active share with absolute clarity may not be possible, but it should not be allowed to remain a fuzzy number!

Barry M. Gillman, CFA, is a principal at Longevity Financial Consulting, Fort Lee, New Jersey. This article includes ideas and suggestions from Peter Branner, CEO of SEB Investment Management $A B$ in Stockholm, Sweden. 